\title{
A METHODOLOGICAL APPROACH FOR PRIORITIZING WATER REUSE PROJECTS IN AGRICULTURAL IRRIGATION: A CASE STUDY IN SPAIN
}

\author{
Antonio Bolinches ${ }^{\mathrm{a}, \mathrm{b}}$, Irene Blanco-Gutiérrez ${ }^{\mathrm{c}, \mathrm{d}, *}$, Sergio Zubelzu ${ }^{\mathrm{e}}$, Paloma Esteve ${ }^{\mathrm{c}, \mathrm{d}}$, Almudena \\ Gómez-Ramos ${ }^{\mathrm{f}}$
}

${ }^{a}$ Fundación General de la Universidad Politécnica de Madrid (Madrid, antonio.bolinches@upm.es). ${ }^{b}$ Fundación Botín, Observatorio del Agua (Madrid). ${ }^{c}$ Departamento de Economía Agraria, Estadística y Gestión de Empesas, Universidad Politécnica de Madrid (Madrid, irene.blanco@upm.es, paloma.esteve@upm.es). ${ }^{d}$ CEIGRAM, Universidad Politécnica de Madrid (Madrid). ${ }^{e}$ Departamento de Ingeniería Agroforestal, Universidad Politécnica de Madrid (Madrid, sergio.zubelzu@upm.es). ${ }^{f}$ Departamento de Ingeniería Agrícola y Forestal. Universidad de Valladolid (Palencia, mariaalmudena.gomez@uva.es)

\begin{abstract}
Water reuse is a strategic priority for Water Authorities in Europe to reduce the pressure on water resources. However, its implementation is lagging behind expectations largely due to financial concerns. In this context, there is a special interest to identify in which specific Wastewater Treatment Plants it would be interesting to add a Water Regeneration Plant, taking account of potential existing clients in the vicinity and the implied costs and benefits. This paper proposes a methodology to quantify the infrastructure and operation costs of project implementation, and the benefits generated by the additional water offer. An algorithm designs the distribution network, allowing for a quick infrastructure cost analysis. The methodology is applied to the Upper Guadiana in Central Spain, where irrigation led to the overexploitation of the local aquifers and the subsequent restrictions on water use. Taking account of the existing Wastewater Treatment Plants, candidate reuse projects are classified according to their benefit/cost ratio, showing large differences according to the location and potential use of the regenerated water. The methodology allows for a quick assessment of the costs and benefits implied in different reuse projects and scenarios, providing science-based evidence to support water policy decisions.
\end{abstract}

Key words: Wastewater treatment, Reclaimed water, Network optimization, Cost and Benefit Analysis, Irrigation.

\section{Introduction}

The growing competition on water abstraction for urban, industrial, agricultural, and other uses, and the perspective of diminishing availability due to climate change are pushing the agenda for the quest of alternative water sources, in particular, water reuse [UN-Water (2020)].

Previous studies [TYPSA (2013)] show the potential for water reuse in Europe, where Spain stands out as the country with the higher yearly reuse volume, and the country with the higher potential in the short term.

In the European Union (EU), numerous initiatives have been recently put in place to foster wastewater reuse, promoting a more resource-efficient circular economy. The maximization of treated wastewater reuse for irrigation has been underlined as a specific objective in several Communications by the Commission ('A Blueprint to Safeguard Europe's Water Resources' (2012), and 'Closing the loop - An EU action plan for the circular economy' (2015)), and identified as a top priority in the Strategic Implementation Plan of the European Innovation Partnership on Water.

Despite the potential of water reuse and its political momentum in the EU, there is limited research regarding the criteria to prioritize water reuse projects, considering the tradeoff between their costs and the potential benefits involved [Arborea et al. (2017); Arena et al. (2020)].

In this paper we propose a methodology to estimate the costs of implementing a water reuse project (initial investment in the reuse plant and distribution network, operation, and maintenance costs), then estimating the benefits of the additional productivity of the agricultural fields irrigated with the reused waters. This allows the organization of candidate reuse projects according to their cost and benefit ratio, supporting Water Authorities to prioritize projects with better prospects.

The proposed methodology streamlines the process through the minimization of the inputs (Wastewater treatment plant location and capacity, potential client's location and irrigation water needs. The definition of the pipe distribution network is automated through the design of an algorithm based on Minimum Span Trees [Jarník (1930); Prim (1957)]. The additional benefits of agricultural uses are also calculated, and the methodology allows for other potential uses (industrial, urban) of regenerated water, given their water consumption and monetarized benefits. The flexibility facilitates the definition of alternative scenarios and provides solid scientific evidence to support water policy decisions. 
The methodology is applied in the Upper Guadiana area in Central Spain, where overexploited aquifers can no longer provide for the water volumes required by agricultural users. The regeneration of a portion of the wastewater generated by the urban agglomerations may alleviate the pressure on water resources.

\section{Methodology}

We propose a Cost-Benefit Analysis (CBA) method to systematically quantify all the costs and benefits of the water reuse projects, in order to assess their economic feasibility. Although new decision support tools are currently being developed to support pre-feasibility studies on water reuse projects, CBA remains the major appraisal method to assess water-related investments [Molinos-Senante et al. (2010)].

The methodology is summarized in Graph 1.

Graph 1. Proposed methodology. WWTP: Wastewater Treatment Plant. CAPEX: Initial investments. OPEX: Operation and maintenance costs.

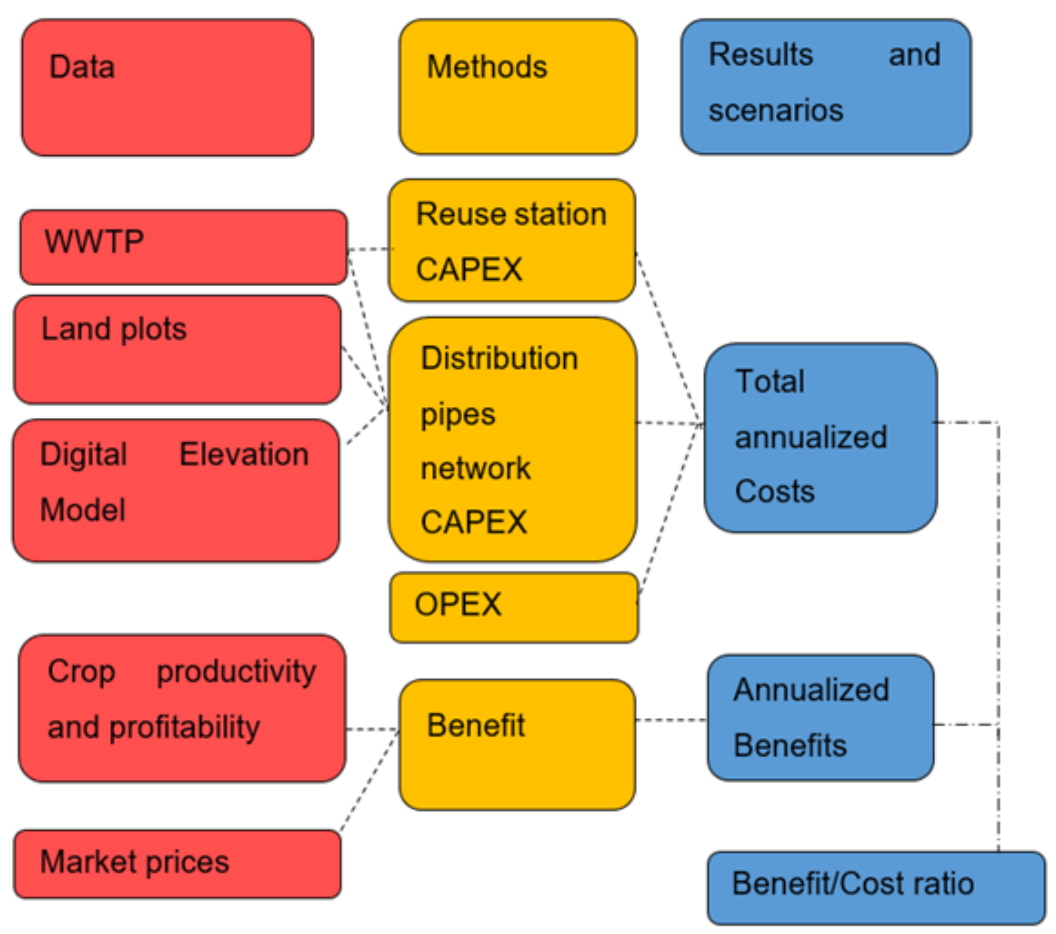

Given a WWTP capacity, the costs (both initial investment and operation) of regenerating the water to reuse standards are assessed. If water uses are not simultaneous to regenerated water production, a storage tank can be envisaged, and its costs assessed. For a geographical setup of potential users, a distribution network is automatically generated through a purpose-developed algorithm. The algorithm proposed in this paper [Bolinches et al. (2021)] exploits the initial data (Water Regeneration Plant position, elevation and water availability; water clients position, elevation and water needs) to design a distribution network (set of pipes with initial and final positions, length and diameter) that connects all users to the water source minimizing the cost.

Once the length and diameter of connection pipes are known, their supply and installation costs are assessed. Given the relative elevation of WWTP and water users, the friction head losses through the distribution network and the required water pressure at each distribution point, a pumping unit is sized, and the investment and operation costs are assessed. The initial investment costs are then annualized using a financial function in order to perform the analysis in monetary units per year [European Commission (2003)].

On the benefit side, each user is characterized by the annual volume of water required and the monetarized benefit generated by the use of the water. The study assumes that irrigating with reclaimed wastewater would allow for changing from rain fed to irrigated crop production. Thus, the benefits associated to reclaimed wastewater use are calculated as the difference between irrigated and rain fed crop gross margins per hectare. A selection of the most relevant crop types in the area was used for the analysis, namely vineyard, olives, horticulture (particularly melon and onion), and cereals. 
Once the total costs and benefits are assessed for each candidate project, the potential net benefit can be calculated, and projects can be prioritized according to their investment returns. The flexibility of the methodology allows for the creation of different scenarios that facilitate the optimization of the process. In particular, the methodology allows for the quantification of the effects of the yearly regeneration period (whether the water regeneration plant works all year long or only in the irrigation months) and the choice of output water quality and process technologies.

\section{Results}

Results are only presented for the baseline scenario. Graph 2 shows the cost and benefit structure of the Tomelloso project. The inner ring shows the percentage of irrigated area covered by each crop type. The middle ring displays the annual benefit generated by the transition from rainfed to irrigated crops, showing the larger benefit potential of the vineyard crops. Finally, the outer ring shows the annual operation cost breakdown and the net benefit of the project.

The analysis shows that most of the benefit is generated through the irrigation of vineyard crops. The highest annual cost is represented by the operation and maintenance of the water regeneration station, followed by the annualized costs of the initial investment of the station. These are followed by other initial costs (storage and distribution infrastructure), while the pumping costs are comparingly smaller. This cost structure is similar in the other candidate projects.

Since the cumulative benefits are larger than the cumulative costs, the project generates a net benefit of $162433 \mathrm{EUR} /$ year.

Graph 2. Cost and benefit structure of the Tomelloso project

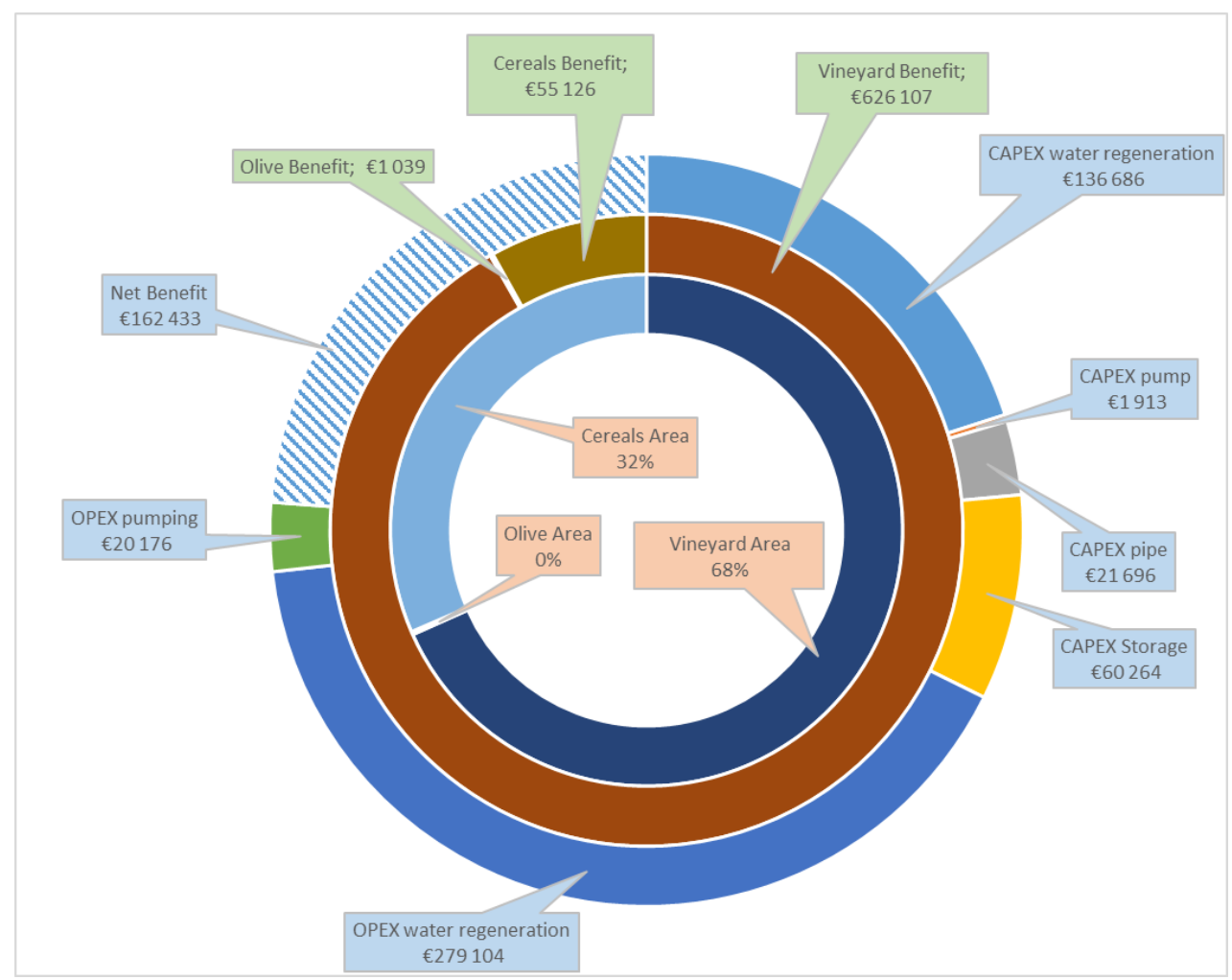

Considering the variety of assumptions, the net benefit should not be taken as an absolute result but rather as a tool of comparison. Under the baseline assumptions, candidate projects can be organized according to their return of investment. Graph 3 shows a wide range of results, depending on the local geometry and the crop types. Projects with a high percentage of high value crops in the proximity of the WWTP are likely to produce net benefits, while candidate projects with a bigger share of low value crops in the vicinity may present losses. The methodology is able to quantify these values and provide alternative scenarios. 
Graph 3. Prioritization of projects according to expected net benefit ratio.

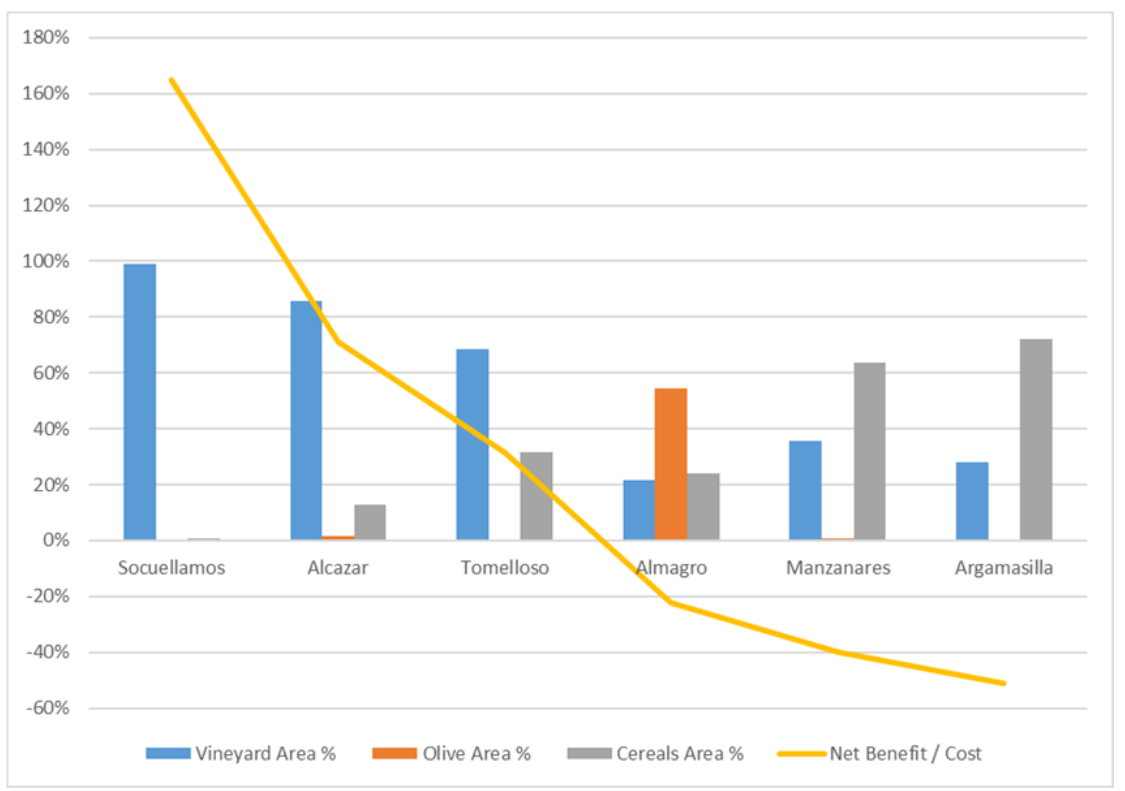

\section{Conclusions}

The proposed methodology can analyze the relative weights of the different cost and benefits of a particular regeneration project with low requirements of initial data and time. Regeneration project candidates with higher potential benefits can be identified, and different scenarios can be projected to optimize the choice of design variables: annual volume of regenerated water, storage and distribution costs, regeneration technology.

In the Upper Guadiana where the methodology is applied, results show that prioritization is driven by the benefits obtained, rather than the cost structure that has minor differences between projects. The generation of net benefits is restricted to candidate projects where high benefit crops are present in the vicinity of the Wastewater Treatment Plant. The regeneration plant initial investment and operation and maintenance costs represent the biggest portion of the overall costs.

\section{References}

Arborea, S., Giannoccaro, G., de Gennaro, B., Iacobellis, V. y Piccinni, A. (2017). "Cost-benefit analysis of wastewater reuse in Puglia, Southern Italy". Water, 9: 175. https://doi.org/10.3390/w9030175

Arena, C., Genco, M. y Mazzola, M.R. (2020). "Environmental benefits and economical sustainability of urban wastewater reuse for irrigation-A cost-benefit analysis of an existing reuse project in Puglia, Italy". Water, 12: 2926. https://doi.org/10.3390/w12102926

Bolinches, A., Blanco, I., Zubelzu, S., Esteve, P. y Gómez-Ramos, A. (2021). WaterReuseDistributionNetwork (Version 1.0) GitHub Repository. https://github.com/RECLAMOCEIGRAM/WaterReuseDistributionNetwork.git. DOI: 10.5281/zenodo.4662471.

European Commission (2003). Guidance document $n .{ }^{\circ} 1$ Economics and the environment.

Jarník, V. (1930). On a certain problem of minimization. Práce Morav. Př́rodovědecké společnosti, 4: 5763.

Molinos-Senante, M., Hernández-Sancho, F. y Sala-Garrido, R. (2010). "Economic feasibility study for wastewater treatment: A cost-benefit analysis". Science of the Total Environment, 408: 4396-4402. https://doi.org/10.1016/j.scitotenv.2010.07.014

Prim, R.C. (1957). "Shortest connection networks and some generalizations". The Bell System Technical Journal, 36: 1389-1401. https://doi.org/10.1002/j.1538-7305.1957.tb01515.x

TYPSA (2013). Update of the final report on wastewater reuse in the European Union. Service contract for the support to the follow-up of the Communication on Water Scarcity and Droughts, Report for DG ENV.

UN-Water (2020). Water and Climate Change. URL https://www.unwater.org/water-facts/climate-change/ (accessed 11.01.21). 